\title{
Assessment of teachers' health in relation to working conditions
}

\section{Dumitru Cheptea}

\author{
Discipline of Hygiene, Department of Preventive Medicine \\ Nicolae Testemitanu State University of Medicine and Pharmacy, Chisinau, the Republic of Moldova
}

Author's ORCID iD, academic degrees and contributions are available at the end of the article

Corresponding author - Dumitru Cheptea, e-mail: dumitru.cheptea@usmf.md

Manuscript received October 25, 2021; revised manuscript November 16, 2021; published online November 25, 2021

\begin{abstract}
Background: Teaching in schools has been defined as the profession with the most diverse risk factors that affect health. With almost 48000 people currently working in educational institutions, teachers make up the largest occupational group in the Republic of Moldova.

Material and methods: The study involved 519 teachers from pre-university educational institutions. For the self-assessment of the health status, a questionnaire was created which was applied online. The subjective assessment was performed by researching the entries in the medical cards.

Results: The majority of respondents were women $(91.4 \%)$, with a mean age of $45.6 \pm 7.5$ years and a working experience of $22.9 \pm 3.2$ years. In $75.7 \%$ of them health is satisfactory, only $3 \%$ have serious health problems and would require hospitalization. In $35.8 \%$ of cases, the presence of chronic diseases is registered, their top being led by diseases of the gastrointestinal tract (33.8\%), the cardiovascular system (29.2\%) and endocrine (27.2\%). The most common risk factors mentioned were: high levels of stress (53.5\%); increased number of tasks (23.4\%); lack of support from family and colleagues (22.9\%). Conclusions: The health of teachers is influenced by a variety of risk factors. There were no correlations between the type of institution and the subject taught, which highlights the importance of studying the influence of factors in the occupational environment and the development of prevention measures. Key words: teachers, health status, risk factors, preventive measures.
\end{abstract}

\section{Cite this article}

Cheptea D. Assessment of teachers' health in relation to working conditions. Mold Med J. 2021;64(5):51-55. https://doi.org/10.52418/moldovanmed-j.64-5.21.10.

\section{Introduction}

Human health is considered one of the most important tasks of the society of any state in the world. In this context, at the current stage of development, the problem of teacher's health is mentioned as a global problem [1,2]. The health of a modern individual is influenced by a multitude of physical, chemical, biological, social factors, and reflects the integral system of material and spiritual relationships existing in society [3]. It largely depends on the quality of the environment, the level of development of society, working conditions, professional level, material condition, the organization of health care.

The teacher, in his professional and social role is a key figure in the educational process, a bearer of special knowledge, as well as a model of behavior and attitude towards health. Currently, the activities of teachers in the Republic of Moldova are not limited to teaching lessons in classrooms. In addition, they must prepare for lessons, evaluate students' exercises, carry out guidance activities, prepare for external school reviews, participate in continuous professional development, and meet the demands of management [4]. Addressing the issue of the influence on health of different categories of factors, it is necessary to address the aspects of the professional activity of teachers. As a result, teachers may suffer from mental and physical health problems due to the diversity of functions and extended overtime.
Even among young teachers there is a large percentage of patients with chronic diseases, and the leading one is cardiovascular pathology $[1,2,5]$. And only $9 \%$ of teachers are healthy, they maintain a relatively high level of efficiency and don't present a chronic disease. Most of them have "iron nerves" by nature, or they have learned to quickly recover mentally after a shift of home rest [5].

Consequently, the profession of a teacher comes first in terms of work intensity and the presence of harmful factors in the workplace [5]. The main harmful factors of pedagogical activity are: physical, emotional overstrain, a high degree of tension of the sensory load on the organs of sight and hearing, a heavy load on the laryngeal vocal apparatus, a high density of epidemic contacts, and the effect of electromagnetic waves [6].

Another risk factor that has a major action on health is the rapid change of modern lifestyle which in recent times is associated with increasing requirements to have new skills, the need to adapt to new types of work as examples of online teaching, the pressure of higher productivity and quality of work, the pressure of time indicating the need for priority action in improving the psychosocial environment of jobs [7].

Epidemiological, clinical and experimental studies show that high levels of acute or chronic stress adversely affect the functions of the human body. Stressors have a significant impact on the physical and emotional well-being of teachers. There is a strong relationship between stress and 
several inflammatory, metabolic, reproductive, autoimmune disorders. It is well known that all the biological systems of the human body are affected by stress [8]. The main chronic diseases of our time appear against the background of emotional experiences, acute or chronic stress. According to the literature, up to $70 \%$ of diseases are associated with emotional stress. More than a million people die in Europe each year due to influence of stress on cardiovascular system $[8,9]$.

The aim: to assess the teachers' status of health working in general primary and secondary educational institutions.

\section{Material and methods}

In order to achieve the proposed goal, a descriptive cross-sectional study was carried out, with some prospective elements. The initial stage consisted of the elaboration of a structured questionnaire that was applied to teachers working both physically and online during the COVID-19 pandemic. The questionnaire included 14 chapters, such as: general data, working and living conditions, eating behavior, subjective assessment of health and objective assessment of changes caused by online teaching. This questionnaire contains a total of 159 questions, of which 96 are required to determine the demographic grade and general clinical condition of each person (general health, living and working environment, family environment). The remaining questions are grouped as follows: 37 refer to teachers' nutrition and 24 were organized in the form of a psychological questionnaire in which respondents rated statements with grades from 0 to 5 . The questionnaire includes closed questions (yes/no type), as well as questions with a variant or variants with multiple answers.

The questionnaire was applied to teachers who meet the following participation criteria: teachers from general primary and secondary education institutions who signed the informed consent and agreed to complete the questionnaire; people of any gender (men, women); people from urban and rural areas without ethnic restrictions; people up to 63 years old.

\section{Study variables}

The influence of occupational environmental factors on health such as occupational stress and burnout was analyzed as follows.

\section{Assessment of psychological burnout}

The Maslach Burnout Inventory (MBI) was used to assess the level of burnout. The instrument measures three constructs: Emotional Exhaustion (EE) (9 items), Depersonalization (DP) (5 items) and Lack of Personal Accomplishments (8 items). Thus, a high level of burnout involves subjects getting high scores on exhaustion subscales (e.g., I feel exhausted from work, I feel like I am run out of power), and depersonalization (e.g., I do not really care about what happens to some of my students).

\section{Assessment of occupational stress}

To assess the level of occupational stress, the "Impact of Event Scale - Revised (IES-R)" tool was applied, which is a short self-report questionnaire that is easy to administer, it has 22 questions. The tool, an appropriate instrument to measure the subjective response to a specific traumatic event in the older adult population, especially in the response sets of intrusion (intrusive thoughts, nightmares, intrusive feelings and imagery, dissociative-like re-experiencing), avoidance (numbing of responsiveness, avoidance of feelings, situations, and ideas), and hyperarousal (anger, irritability, hypervigilance, difficulty in concentrating, heightened startle), as well as a total subjective stress IES-R score.

The collected data was entered in Microsoft Excel 2007 and statistical analysis was performed using Statistical Package for Social Sciences (SPSS) version 23. Qualitative variables, such as gender, socioeconomic status and morbidity profile were summarized as frequencies and percentages. Quantitative variables, such as age and hours of work were expressed as mean and standard deviation.

\section{Results}

Of the 750 teachers included in the study, 519 people completed the questionnaire, which represents a response rate of $69.2 \%$. The sample consisted of teachers, department heads and principals from a single school board, with a mean age of $45.6 \pm 7.5$ years and a working experience of $22.9 \pm 3.2$ years. The selection of teachers was carried out randomly so as to cover the entire territory of the Republic of Moldova. Table 1 depicts the distribution of baseline sociodemographic characteristics and occupational characteristics among the sample.

Table 1. General characteristics of study subjects $(\mathrm{N}=519)$

\begin{tabular}{|c|c|c|}
\hline Variables & $\begin{array}{l}\text { Frequency } \\
\text { (n) }\end{array}$ & $\begin{array}{c}\text { Percentage } \\
\text { (\%) }\end{array}$ \\
\hline \multicolumn{3}{|l|}{ Sociodemographic characteristics } \\
\hline $\begin{array}{l}\text { Age: } \\
>25 \text { years } \\
25-30 \text { years } \\
30-35 \text { years } \\
35-40 \text { years } \\
40-45 \text { years } \\
45-50 \text { years } \\
50-55 \text { years } \\
55-60 \text { years } \\
<60 \text { years }\end{array}$ & $\begin{array}{c}9 \\
34 \\
71 \\
91 \\
81 \\
112 \\
58 \\
36 \\
27\end{array}$ & $\begin{array}{c}1.7 \\
6.6 \\
13.7 \\
17.6 \\
15.6 \\
21.4 \\
11.2 \\
6.9 \\
5.2\end{array}$ \\
\hline $\begin{array}{l}\text { Gender } \\
\text { Male } \\
\text { Female }\end{array}$ & $\begin{array}{c}475 \\
44\end{array}$ & $\begin{array}{l}91.5 \\
8.5\end{array}$ \\
\hline $\begin{array}{l}\text { Marital status } \\
\text { Currently married } \\
\text { Single } \\
\text { Widowed } \\
\text { Divorced }\end{array}$ & $\begin{array}{l}442 \\
29 \\
20 \\
28\end{array}$ & $\begin{array}{c}85.2 \\
5.6 \\
3.9 \\
5.4\end{array}$ \\
\hline $\begin{array}{l}\text { Educational status of participants } \\
\text { Undergraduate } \\
\text { Postgraduate } \\
\text { Others }\end{array}$ & $\begin{array}{c}26 \\
426 \\
67\end{array}$ & $\begin{array}{c}5.0 \\
82.1 \\
12.9\end{array}$ \\
\hline
\end{tabular}




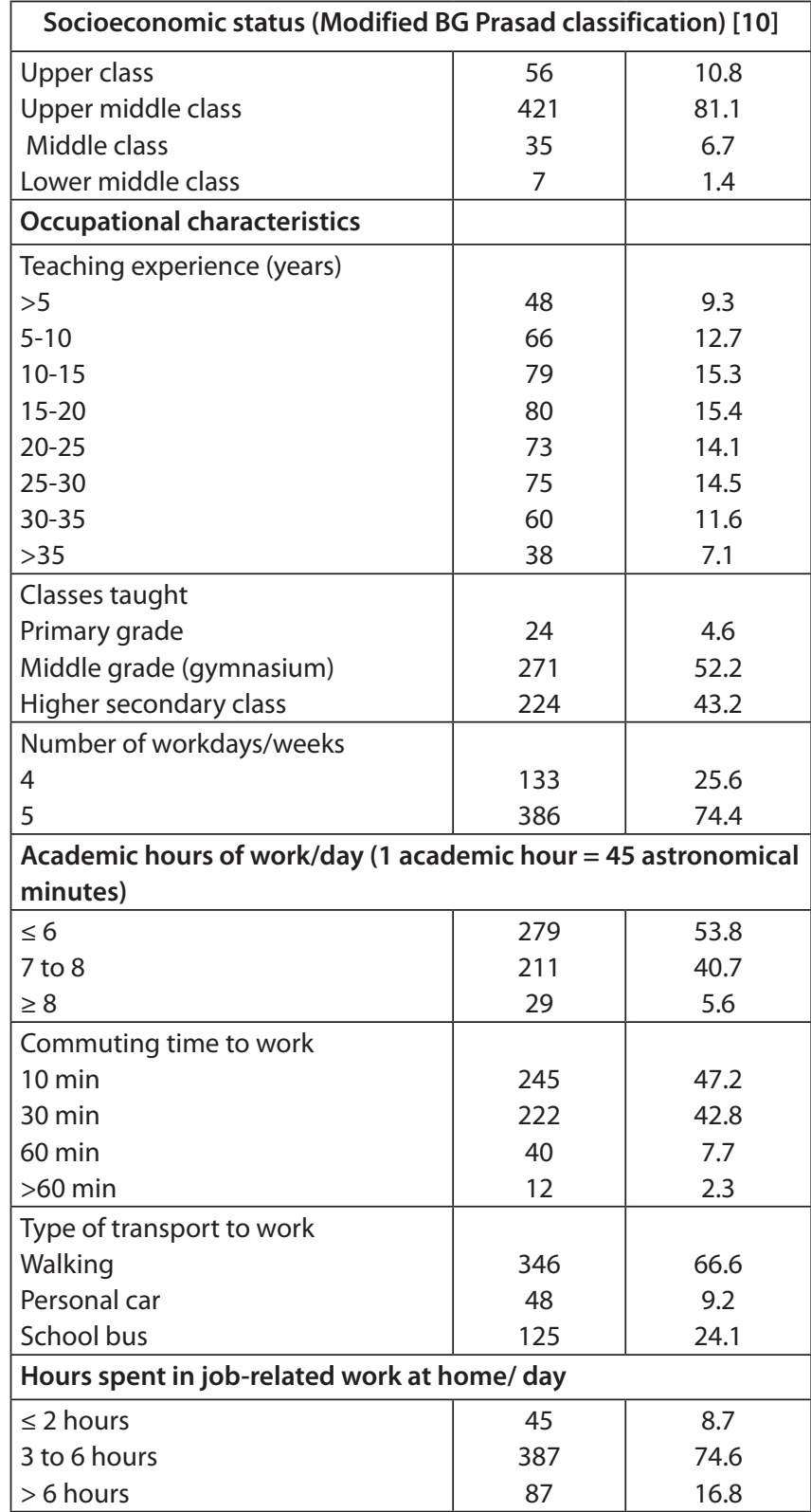

In order to identify the main risk factors in the occupational environment, the answers of the respective category were analyzed. With the help of the questionnaire we proceeded to the subjective evaluation of the conditions of the occupational environment. Of all the participants in the study, 197 people (38\%) reported an orthostatic position (standing) throughout the work period, 20.6\% - sitting, $41.4 \%$ - with class trips. Brightness level assessment more than $82.3 \%$ rated a sufficient level of light, and only $13.5 \%$ accused insufficient lighting levels. Unstable summerwinter temperature levels accounted for $10.8 \%$ of teachers. In order to have a more general overview, the answers to the statements about the physical environment were scored, the positive perception being assigned a score of «1» and the negative perception assigned a score « $0 »$, so that the higher the score, the perception of the physical environment at work is more positive. The average score was $6.25 \pm 1.82$.

Study participants in $75.7 \%$ of cases report a satisfactory health status and only $3 \%$ have serious health problems and would need hospitalization. Unfortunately, a large number of teachers $(7.5 \%)$ do not know their health status because they are not provided with quality primary health care. Analyzing the share of chronic diseases, it can be concluded that most teachers do not suffer from chronic diseases (52.2\%). Chronically ill people (35.8\%) usually get sick more in the winter-spring period (46.7\%) and the autumn $(38.8 \%)$. Again, it becomes a problem that $11.9 \%$ of teachers do not know whether or not they suffer from any chronic diseases, the reason being the lack of specialists in the region, the impossibility to go to a private clinic and the insurance of the rural medical system. Among the participants suffering from chronic diseases, $29.2 \%$ of them suffer from diseases of the gastrointestinal tract, $16.8 \%$ - the articular system, $29.4 \%$ - cardiovascular system, $33.6 \%$ - the endocrine system, $21.0 \%$ - respiratory system and $12.6 \%$ - nervous system. Table 2 shows the distribution of workplace-related morbidity experienced by the participants in the last year.

Table 2: Workplace-related morbidity profile of study subjects in the last year year $(\mathrm{N}=519)$

\begin{tabular}{|l|c|c|}
\hline \multicolumn{1}{|c|}{ Variables } & $\begin{array}{c}\text { Frequency } \\
\text { (n) }\end{array}$ & $\begin{array}{c}\text { Percentage } \\
\text { (\%) }\end{array}$ \\
\hline Injury & 29 & 5.58 \\
\hline Respiratory symptoms & 477 & 91.9 \\
\hline Sleep disturbances & 378 & 72.8 \\
\hline Eye strain & 463 & 89.2 \\
\hline Voice strain & 176 & 33.9 \\
\hline Headache & 507 & 97.7 \\
\hline Ear pain or hearing disturbances & 466 & 89.8 \\
\hline Musculoskeletal disorders: & & \\
Ankle/ feet & 117 & 22.5 \\
Knees & 59 & 11.4 \\
Lower back & 93 & 17.9 \\
Neck & 72 & 13.9 \\
\hline
\end{tabular}

Analyzing the structure of morbidity among teachers it can be concluded that diseases of the gastric tract are predominant (33.8\%) followed by diseases of the cardiovascular system (29.2\%). This can be explained by analyzing the nutritional style as well as the nature of the work performed. Increased levels of stress due to poor nutrition are the main predictors of this structure. Allergic diseases also play a key role. Their appearance is usually due to the presence in the air of the occupational environment of a stable concentration of dust produced by wiping the classrooms.

For the subsequent characteristic of the influence of risk factors in the occupational environment and their action on teachers' health, a correlation analysis was used. To estimate the simultaneous comorbidity of different diseases at the individual level, the dichotomized responses were further combined into three ordered categories: $0=$ subjects who report a low level of frequency of acute diseases or low level of chronic diseases (referents); 1 = subjects who report either a high frequency of acute diseases or a high frequency of chronic diseases (one of the 2 dimensions); $2=$ 
Table 3. Mean, standard deviations (SD), and latent correlation between all factors

\begin{tabular}{|c|c|c|c|c|c|c|c|c|c|c|c|}
\hline Variable & Mean & SD & 1 & 2 & 3 & 4 & 5 & 6 & 7 & 8 & 9 \\
\hline 1. Gender & 1.42 & 0.49 & - & & & & & & & & \\
\hline 2. Years of professional experience & 22.9 & 3.20 & $0.23^{*}$ & - & & & & & & & \\
\hline 3. Number of working hours & 6.9 & 1.34 & $0.09^{*}$ & $-0.71^{* *}$ & - & & & & & & \\
\hline 4. Number of working days & 4.8 & 0.37 & $0.05^{*}$ & $-0.39 *$ & -0.12 & - & & & & & \\
\hline 5. Increased number of tasks & 4.3 & 2.2 & $0.05^{* *}$ & $0.37^{*}$ & 0.34 & 0.05 & - & & & & \\
\hline $\begin{array}{l}\text { 6. Sudden change of teaching type } \\
\text { (switching to online teaching only) }\end{array}$ & 1.7 & 0.52 & 0.60 & $-0.74^{* *}$ & $0.64^{*}$ & $0.39 * *$ & $0.05^{*}$ & - & & & \\
\hline 7. Occupational stress & 11.9 & 4.99 & $0.015^{* *}$ & $-0.05^{*}$ & $0.31^{*}$ & $0.03^{*}$ & $0.12^{*}$ & $0.77^{*}$ & - & & \\
\hline 8. Burnout (MBI score) & 58.3 & 17.78 & $-0.18^{*}$ & $-0.11^{*}$ & $0.45^{*}$ & $0.29^{*}$ & $0.51^{*}$ & $0.61^{*}$ & $0.11^{* *}$ & - & \\
\hline 9. Health status & 2.3 & 1.08 & $-0.22^{*}$ & $0.65^{* *}$ & 0.12 & $0.31^{*}$ & 0.22 & $-0.07^{*}$ & $0.56^{*}$ & $0.71^{*}$ & - \\
\hline
\end{tabular}

Note: ${ }^{*} \mathrm{p}<0.05,{ }^{* *} \mathrm{p}<0.001$

subjects who report a high frequency of acute diseases and / or a high frequency of chronic diseases (all 2 dimensions). Table 3 demonstrates the average, standard deviation and correlation relationships between the main risk factors in the occupational environment and the incidence of various diseases in teachers.

\section{Discussion}

This study expands previous research literature on teachers' health status and the influence of occupational factors, such as emotional exhaustion by examining the direct and indirect relationships between health status and perceived stress and burnout in a sample of teachers. The basic reasoning was that health status can be improved by reducing perceived stress, which in turn would promote lower levels of teachers' exhaustion, regardless of gender, age, and level of teaching.

A series of empirical evidence has been accumulated proving that deficits in emotional abilities are directly related to increased incidences of both chronic and acute illnesses, due in large part to the influence of psychosocial factors and especially burnout $[2,9]$. Consistent with these findings, this research provided evidence that health was directly correlated with both perceived sense of stress and burnout symptoms. Specifically, teachers who report being emotionally poor in their perception and management of emotions also tend to report that they feel more exhausted and more cynical about their work and the students they work with, less sense of personal fulfillment. This in turn tends to be a strong predictor of the installation of various disorders of the central nervous system, demonstrated in previous studies.

One explanation for these findings is that the skills of teaching professionals to effectively manage emotional challenges are characterized by more constructive thought patterns, and it is easier for teachers to catch and identify misjudgments and correct misinterpretations in the workplace. In addition, it is possible that teachers who are more emotionally competent would also feel that they have more control over their stressful environment because they can confer sense and manage their negative moods associated with stress more adaptively.

According to previous studies, it was established that about $70 \%$ of respondents reported deviations in their health. The most common pathological forms were: visual disorders - 68\%; cardiovascular diseases - 48\%; musculoskeletal disorders $-44 \%$ [11]. There is also a high incidence of polyorganic deficiency syndrome [12]. These pathologies are largely caused by prolonged exposure to stress, sedentary lifestyle and other social factors.

Proceeding from this, the professional activity of a teacher in modern conditions does not contribute to the preservation and strengthening of his health, as evidenced by the following data: $60 \%$ of teachers constantly experience psychological discomfort during work; $85 \%$ are in a constant state of stress: for $85 \%$ of women teachers, their activities are a factor that negatively affects family relations, as a result of which $1 / 3$ of teachers have nervous system disorders [5]. Only $10.4 \%$ did not demonstrate health problems.

The workload of teachers at this stage includes many tasks, such as teaching students, preparing lessons, evaluating students' homework and extracurricular activities. As a result of these extended duties, school teachers may have physical and mental health problems. Musculoskeletal pain is the main reason for absenteeism and early retirement for teachers in Saudi Arabia [13].

The present study shows that most teachers have faced at least one physical health problem at work in the last year and most teachers have experienced moderate and high levels of stress due to the environment at work. Such results have been demonstrated by other authors, such as Geetha Mani in her study "Occupational health assessment of teachers in selected schools in Vellore district", Tamil Nadu: "Role of workplace environment in health" [7]. Also, in the same study it was highlighted that occupational stress is identified 
among the main factors predisposing to the occurrence of musculoskeletal disorders.

Arvidsson I. and the authors also came to the conclusion about the negative action on the effectiveness of teachers in the study "Burnout among Swedish school teachers - a cross-sectional analysis" [14] where it was identified that high levels of emotional exhaustion had a direct correlation with the occurrence of health problems characteristic also for teachers from the Republic of Moldova.

Given the limitations of the present study, future research should include longitudinal models to test the stability over time of received findings. Although the obtained results do not lend themselves to deducing causality, they suggest that training the above risk factors and their influence on teachers' health could help alleviate the psychological symptoms associated with work-related stressors. In addition, it is recommended to include additional variables (e.g. resilient adaptation or positive affect) to gain a better understanding of the mechanism by which they, especially psychosocial factors, can function in improving the health and well-being of teachers. It was also argued that selfreporting of health is not always in correspondence with the entries in medical cards, which proves that the latter are not completed qualitatively. This sample was similar to previous heterogeneous and large samples; however, studies with larger samples are needed that can compare the results according to the level of teaching, because the predictive value of this factor allows the design of more effective intervention programs on emotional preparation.

\section{Conclusions}

This research showed a high prevalence of chronic as well as acute diseases in teachers, largely due to the pandemic situation. Another problem was the high levels of stress that most often or due to too many activities in which teachers are involved and insufficient rest. Another factor with a strong influence was the high levels of burnout which was directly correlated with the occurrence of health disorders in both young specialists and those with more work experience. Work experience has been shown to be a protective factor in the occurrence of stress at early levels, but which has no statistical connection with teachers' health disorders.

Some useful preventive measures can be implemented at school level to reduce the high prevalence of chronic diseas- es, such as a proportional reduction in workload for older teachers, optimizing working hours per day and the availability of comfortable furniture.

\section{References}

1. Ruijuan Y, Xuqun Y, Yu Z. Teachers' mental health becoming worse: the case of China. Int J Educ Dev. 2019;70:102077. doi: 10.1016/j. ijedudev.2019.102077.

2. Cheptea D, Deleu R, Mesina V, Friptuleac G, Cebanu S. Assessment of burnout among teachers during the COVID-19 pandemic. Arch Balk Med Union. 2021;56(2):179-184. doi: 10.31688/ABMU.2021.56.2.06.

3. Capone V, Petrillo G. Mental health in teachers: relationships with job satisfaction, efficacy beliefs, burnout and depression. Curr Psychol. 2020;39(1):1757-1766. doi: 10.1007/s12144-018-9878-7.

4. Seibt R, Matz A, Hegewald J, Spitzer S. Working conditions of female part-time and full-time teachers in relation to health status. Int Arch Occup Environ Health. 2012;85(6):675-687. doi: 10.1007/s00420-0110715-7.

5. Hamilton L, Goodman L, Roberts L, et al. Teacher's experience, personal health, and dieting status is associated with classroom health-related practices and modeling. J Sch Health. 2021;91(2):155-163. doi: 10.1111/ josh. 12985.

6. Wirth T, Kozak A, Schedlbauer G, et al. Health behaviour, health status and occupational prospects of apprentice nurses and kindergarten teachers in Germany: a cross-sectional study. J Occup Med Toxicol. 2016;11:26. doi: 10.1186/s12995-016-0116-7.

7. Nadeina L. Analiz profesional'noi zabolevaemosti pedagogov [Analysis of the professional morbidity of teachers]. Vesstnik Donetskogo pedagogicheskogo instituta. 2018;(2):134-140. Russian.

8. Bernotaite L, Malinauskiene V. Workplace bullying and mental health among teachers in relation to psychosocial job characteristics and burnout. Int J Occup Med Environ Health. 2017;30(4):629-640. doi: 10.13075/ijomeh.1896.00943.

9. Mani G, Balaji MS, Thirunaaukarasu D, William RF. Occupational health assessment of teachers in selected schools in Vellore district, Tamil Nadu: role of workplace environment in health. Al Ameen J Med Sci. 2019;12(3):139-144.

10. Mérida-López S, Extremera N, Rey L. Emotion-regulation ability, role stress and teachers' mental health. Occup Med. 2017;67(7):540-545. doi: 10.1093/occmed/kqx125.

11. Rey L, Extremera N, Pena M. Emotional competence relating to perceived stress and burnout in Spanish teachers: a mediator model. PeerJ. 2016;4:e2087. doi: 10.7717/peerj.2087.

12. Tabassum N, Rao RLL. An updated Kuppuswamy's socio-economic classification for 2017. Int J Health Sci Res. 2017;7(5):365-367.

13. Abdel-Salam DM, Almuhaisen AS, Alsubiti RA, Aldhuwayhi NF, Almotairi FS. Musculoskeletal pain and its correlates among secondary school female teachers in Aljouf region, Saudi Arabia. J Public Health. 2019. Epub 2019 Jul 29. doi: 10.1007/s10389-019-01127-8.

14. Arvidsson I, Håkansson C, Karlson B, Björk J, Persson R. Burnout among Swedish school teachers - a cross-sectional analysis. BMC Public Health. 2016;16(1):823. doi: 10.1186/s12889-016-3498-7.

\section{Author's ORCID iD and academic degrees}

Dumitru Cheptea, MD, PhD Applicant, Assistant Professor - https://orcid.org/0000-0002-2229-0286

\section{Author's contribution}

DC conceptualized the idea, conducted literature review, collected the data, interpreted the data, and wrote the manuscript.

Funding. This study was supported by Nicolae Testemitanu State University of Medicine and Pharmacy. The trial was the author's initiative. The author is independent and takes responsibility for the integrity of the data and accuracy of the data analysis.

\section{Ethics approval and consent to participate}

The study was approved by the Research Ethics Committee of Nicolae Testemitanu State University of Medicine and Pharmacy (Protocol No 17 of 14.04.2019). An informed consent from all participants in the study was obtained.

Conflict of Interests . There is no known conflict of interests to declare. 